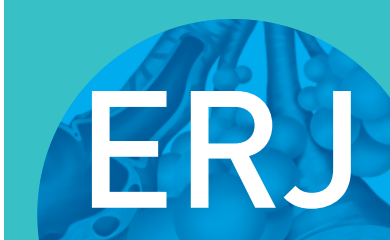

open research

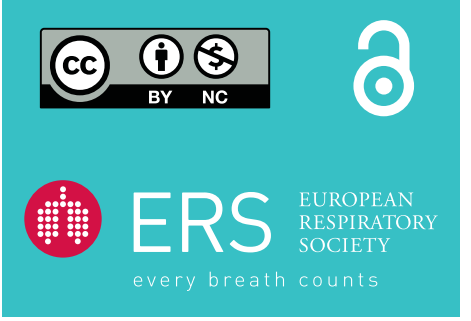

\section{Placing a mask on COVID-19 patients during high-flow nasal cannula therapy reduces aerosol particle dispersion}

\section{To the Editor:}

High-flow nasal cannula (HFNC) has been shown to improve oxygenation and reduce the need for intubation for hypoxaemic patients [1]. A retrospective study reported the effectiveness of HFNC to improve oxygenation of COVID-19 patients [2]. The transmission route of the severe acute respiratory syndrome coronavirus 2 (SARS-CoV-2) virus remains controversial [3], and concerns persist of potentially increased virus transmission when using HFNC among COVID-19 patients [3-5]. Computational fluid dynamics simulations reported that wearing a surgical/procedure mask over HFNC may reduce aerosol droplet dispersion [6]. However, how far those results translate in vivo among infected patients is unknown. Furthermore, the infectious potential of dispersed aerosol droplets is uncertain. Thus, we aimed to investigate the amount of aerosol particles and their size distribution in the vicinity of COVID-19 patients during conventional nasal cannula and HFNC therapy with and without a mask, as well as virus detection in environmental air samples taken during HFNC therapy. Our hypotheses were HFNC would generate similar or lower particle concentrations than conventional oxygen therapy and placing a mask over HFNC would reduce particle concentrations.

This prospective observational study (www.clinicaltrials.gov identifier number: NCT04353531) was approved by the ethics committee (No. 20032402-IRB01, waived informed consent due to lack of contact and intervention) and implemented at Rush University Medical Center. Adult patients with laboratory confirmed COVID-19 and indicated to use HFNC were enrolled. This study was conducted in rooms of $4 \times 4 \times 2.8 \mathrm{~m}$ with a negative pressure of $0.0254 \mathrm{cmH}_{2} \mathrm{O}$ and air exchange frequency of 12 times per hour.

5 minutes before HFNC started, while patients were using conventional nasal cannula (1600HFTLC-7-25; Salter Labs, Lake Forest, IL, USA), two optical particle sizers (Model 3889; Kanomax, Andover, NJ, USA) were placed longitudinally at 1 foot $(30.5 \mathrm{~cm})$ and 3 feet $(91.5 \mathrm{~cm})$ away from the patient's face to measure the aerosol concentration across the particle size distribution (figure 1). HFNC was initiated at $50 \mathrm{~L} \cdot \mathrm{min}^{-1}$ (Airvo2 or Optiflow; Fisher \& Paykel Healthcare, Auckland, New Zealand) with fraction of inspired oxygen $\left(F_{\mathrm{IO}_{2}}\right)$ titrated to maintain pulse oximetry saturation at $92-95 \%$. Per institutional policy, patients were encouraged to wear a surgical/procedure mask over HFNC if tolerated. Particle concentrations were continuously monitored for $5 \mathrm{~min}$ before and $5 \mathrm{~min}$ after the patient started wearing the mask in a semi-Fowler position with the head in neutral position.

A universal pump with a $25 \mathrm{~mm}$ filter cassette and gelatin filters (SKC, Inc. Eighty Four, PA, USA) was used for sampling $10 \mathrm{~L} \cdot \mathrm{min}^{-1}$ of room air for $1 \mathrm{~h}$ after HFNC was initiated [7] and the cassette was placed 1 foot $(30.5 \mathrm{~cm}$ ) away from the patient's face. Following aerosol sampling, $0.5 \mathrm{~mL}$ RNAlater (Thermo Fisher Scientific, Waltham, MA, USA) was added to the filter and cassettes were stored at $4^{\circ} \mathrm{C}$. QIAamp Viral RNA Mini kit (QIAGEN, Hilden, Germany) was used to extract RNA from gelatin filters and excess

@ERSpublications

Wearing a surgical/procedure mask over high-flow nasal cannula (HFNC) reduces aerosol particle concentrations in the patients' vicinity. Wearing a mask over HFNC should be encouraged to reduce risks of aerosol transmission. \#COVID19 https://bit.ly/2HLg5cE

Cite this article as: Li J, Fink JB, Elshafei AA, et al. Placing a mask on COVID-19 patients during high-flow nasal cannula therapy reduces aerosol particle dispersion. ERJ Open Res 2021; 7: 005192020 [https://doi.org/10.1183/23120541.00519-2020].

\footnotetext{
This study is registered at www.clinicaltrials.gov with identifier number NCT04353531. Individual deidentified participant data (including data dictionaries) will be shared per request, beginning 3 months and ending 3 years following article publication.
}

Copyright $\odot$ ERS 2021. This article is open access and distributed under the terms of the Creative Commons Attribution Non-Commercial Licence 4.0. 


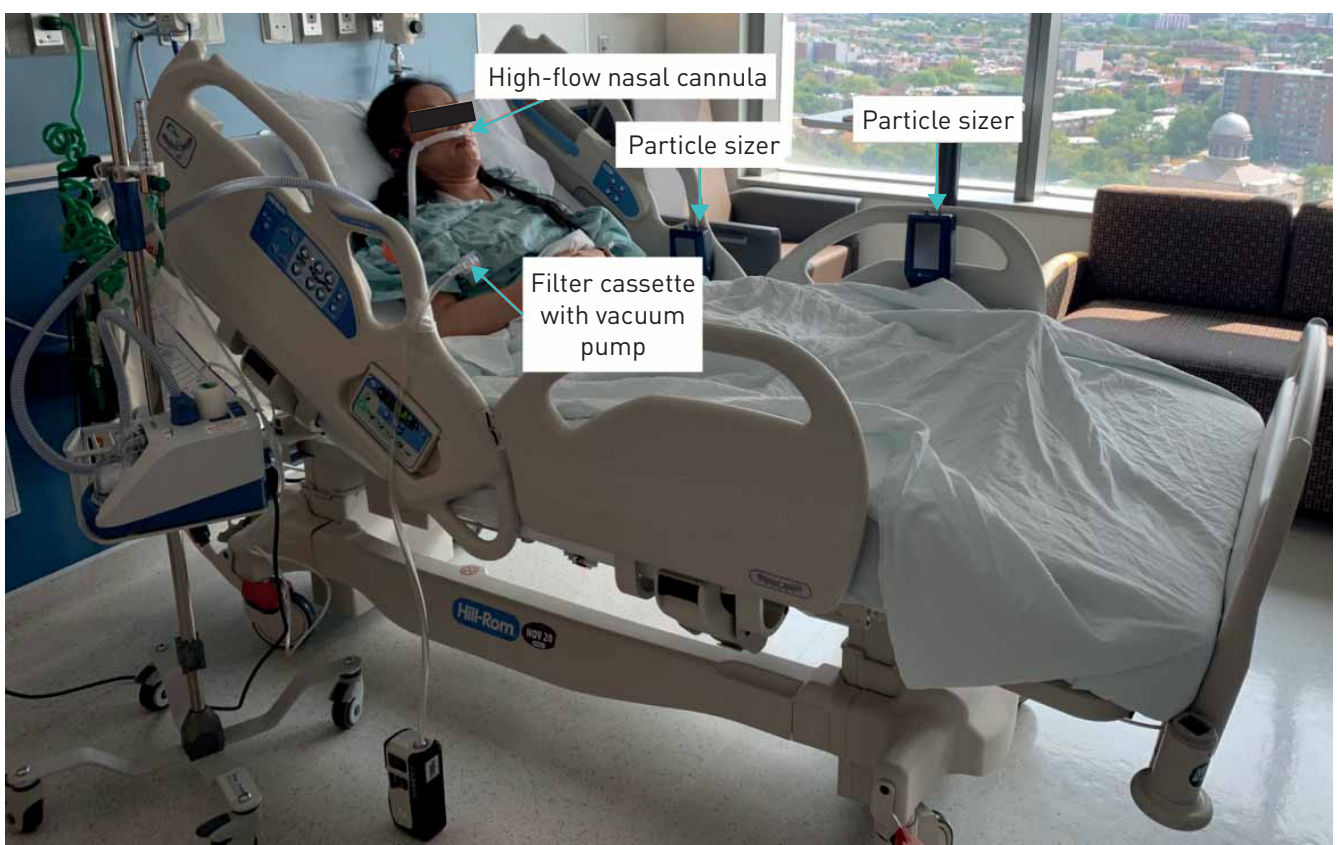

FIGURE 1 High-flow nasal cannula set-up with a filter cassette with vacuum pump for sampling room air to detect SARS-CoV-2 virus and two optical particle sizers placed longitudinally at 1 foot $(30.5 \mathrm{~cm})$ and 3 feet $(91.5 \mathrm{~cm})$ away from the patient's face to measure the aerosol concentrations.

RNAlater. Quantitative reverse transcript PCR (RT-qPCR) was performed on 50\% of the total RNA extract using 2019-nCoV-N2 primers and probes [8]. Serial dilution of positive control plasmids containing the SARS-CoV nucleocapsid gene were used to estimate the limit of detection.

The Wilcoxon sign rank test was used to compare variables across conditions. A p-value $<0.05$ was considered significant. Data analysis was conducted with SPSS software (SPSS 26.0; IBM Corp., Armonk, NY, USA).

Nine patients (five male) were enrolled (mean age: $63 \pm 15$ years). The duration between COVID-19 confirmation and inclusion was 4 days (interquartile range (IQR): 0-7 days). HFNC flow was set at $50 \mathrm{~L} \cdot \mathrm{min}^{-1}$ (IQR: $50-60 \mathrm{~L} \cdot \mathrm{min}^{-1}$ ) while $F_{\mathrm{IO}_{2}}$ was set at 0.60 (IQR: 0.55-0.75). Chest radography showed bilateral multifocal airspace opacities for all patients.

Prior to HFNC, five patients were evaluated during conventional nasal cannula at $11 \mathrm{~L} \cdot \mathrm{min}^{-1}$ (IQR: 10-15 L. $\left.\mathrm{min}^{-1}\right)$, and then switched to HFNC. The remaining four patients were excluded from this analysis, due to the use of noninvasive ventilation $(n=1)$, nonrebreather mask $(n=1)$ prior to HFNC, or the lack of baseline measurement due to the immediate requirement for $\operatorname{HFNC}(n=2)$. For the five evaluated patients, the concentration of particles of $\leqslant 0.3 \mu \mathrm{m}, 0.5-1 \mu \mathrm{m}$ and $1-3 \mu \mathrm{m}$ was slightly lower with HFNC therapy compared with the conventional nasal cannula, at 3 feet $(91.5 \mathrm{~cm})$ away from the patients' face. Larger particles $(>5 \mu \mathrm{m})$ were present in similar amounts (table 1). Among the nine patients, six patients could be evaluated with and without a mask, as three refused or could not tolerate wearing a surgical/ procedure mask during HFNC therapy. The concentration of particles of $0.5-5 \mu \mathrm{m}$ at 1 foot $(30.5 \mathrm{~cm})$ from the head of the patient was lower while wearing the mask. By contrast, concentrations of smaller $(\leqslant 0.3 \mu \mathrm{m})$ and larger $(5-10 \mu \mathrm{m})$ particles were similar in both conditions. At 3 feet $(91.5 \mathrm{~cm})$ away, the concentration of particles was reduced while wearing a mask, but statistical significance was reached only for particles of 1-3 $\mu \mathrm{m}$ (table 1).

None of the room air samples showed detectable SARS-CoV-2 virus genetic material despite a detection limit of two viral copies per reaction.

Wearing a surgical/procedure mask over HFNC reduced the concentration of particles with sizes $0.5-5 \mu \mathrm{m}$, particularly at 1 foot $(30.5 \mathrm{~cm})$ from the patients' face. This finding confirms results of computational fluid dynamics simulations [6]. Large particles $(5-10 \mu \mathrm{m})$ settle at close distance and are more easily blocked by personal protection equipment. In contrast, very small particles $(<0.3 \mu \mathrm{m})$ may more readily pass through and around the mask. Our findings suggest that particles ranging from $0.5-5 \mu \mathrm{m}$ are effectively blocked or diverted by the surgical/procedure mask [3]. These results have important implications for daily clinical 
TABLE 1 Aerosol particle concentrations of different sizes during conventional nasal cannula therapy and high-flow nasal cannula (HFNC) therapy with and without a mask

\begin{tabular}{|c|c|c|c|c|c|c|c|c|c|c|c|c|}
\hline \multirow[t]{3}{*}{ Particle size } & \multicolumn{6}{|c|}{ Conventional nasal cannula ${ }^{\#}$ versus HFNC $(n=5)$} & \multicolumn{6}{|c|}{ HFNC with versus without a mask $(n=6)$} \\
\hline & \multicolumn{3}{|c|}{ Concentration at 1 foot ${ }^{\natural}$} & \multicolumn{3}{|c|}{ Concentration at 3 feet ${ }^{\Uparrow}$} & \multicolumn{3}{|c|}{ Concentration at 1 foot ${ }^{\natural}$} & \multicolumn{3}{|c|}{ Concentration at 3 feet ${ }^{\Uparrow}$} \\
\hline & Conventional cannula & HFNC & $\mathrm{p}$-value & Conventional cannula & HFNC & p-value & No mask & Mask & p-value & No mask & Mask & $\mathrm{p}$-value \\
\hline$\leqslant 0.3 \mu \mathrm{m}$ & $710212 \pm 622173$ & $\begin{array}{l}581273 \pm \\
513067\end{array}$ & 0.138 & $743822 \pm 658053$ & $\begin{array}{c}570318 \pm \\
490647\end{array}$ & 0.043 & $\begin{array}{l}706247 \pm \\
510591\end{array}$ & $\begin{array}{l}706611 \pm \\
531585\end{array}$ & 0.753 & $\begin{array}{l}653710 \pm \\
460070\end{array}$ & $\begin{array}{l}633964 \pm \\
439677\end{array}$ & 0.249 \\
\hline $0.3-0.5 \mu \mathrm{m}$ & $29598 \pm 25464$ & $\begin{array}{c}22914 \pm \\
18332\end{array}$ & 0.686 & $36511 \pm 32609$ & $\begin{array}{l}24666 \pm \\
20414\end{array}$ & 0.08 & $\begin{array}{l}23020 \pm \\
17297\end{array}$ & $\begin{array}{c}21911 \pm \\
17796\end{array}$ & 0.046 & $\begin{array}{c}23275 \pm \\
18722\end{array}$ & $\begin{array}{l}21802 \pm \\
17307\end{array}$ & 0.173 \\
\hline $0.5-1 \mu \mathrm{m}$ & $2821 \pm 1464$ & $2744 \pm 1317$ & 0.50 & $3966 \pm 2758$ & $2593 \pm 1243$ & 0.043 & $2575 \pm 1124$ & $1980 \pm 1083$ & 0.028 & $2380 \pm 1118$ & $2053 \pm 1082$ & 0.173 \\
\hline $1-3 \mu \mathrm{m}$ & $913 \pm 368$ & $876 \pm 436$ & 0.345 & $943 \pm 499$ & $732 \pm 316$ & 0.043 & $758 \pm 348$ & $544 \pm 274$ & 0.028 & $647 \pm 295$ & $501 \pm 252$ & 0.028 \\
\hline 3-5 $\mu \mathrm{m}$ & $436 \pm 166$ & $418 \pm 242$ & 0.50 & $423 \pm 200$ & $355 \pm 179$ & 0.08 & $386 \pm 225$ & $266 \pm 117$ & 0.028 & $319 \pm 171$ & $254 \pm 124$ & 0.116 \\
\hline $5-10 \mu \mathrm{m}$ & $205 \pm 77$ & $194 \pm 127$ & 0.50 & $152 \pm 86$ & $142 \pm 80$ & 0.225 & $197 \pm 177$ & $129 \pm 65$ & 0.173 & $135 \pm 114$ & $107 \pm 58$ & 0.753 \\
\hline
\end{tabular}


practice. Even though the number of very small particles far exceeds larger particles, their probability of containing viral material is much lower (virus size is estimated to be $0.125 \mu \mathrm{m}$, thus only very few may be contained in a $<0.5 \mu \mathrm{m}$ droplet). Furthermore, particles of $0.5-5 \mu \mathrm{m}$ are the most likely to deposit in the respiratory tract of healthcare workers [3]. Thus, reducing their concentration in the patients' vicinity is clinically meaningful, as it may reduce the risk of healthcare workers inhaling aerosol generated by patients.

Compared with conventional nasal cannula at $10-15 \mathrm{~L} \cdot \mathrm{min}^{-1}$, the concentration of aerosol particles $\leqslant 5 \mu \mathrm{m}$ was lower with HFNC therapy at 3 feet $(91.5 \mathrm{~cm})$ from the patients' face, even though significance was not reached across the whole range of particle sizes. Our findings are consistent with reports that particle concentrations with $\mathrm{HFNC}$ at $50 \mathrm{~L} \cdot \mathrm{min}^{-1}$ were lower than with a conventional nasal cannula at $4 \mathrm{~L} \cdot \mathrm{min}^{-1}$ or a face mask at $15 \mathrm{~L} \cdot \mathrm{min}^{-1}$, with particle geometric sizes measured in the 1-2 $\mu \mathrm{m}$ range [9].

SARS-CoV-2 viral RNA was not detected in the room air samples during HFNC treatment of COVID-19 patients, consistent with prior reports that sampled negative pressure rooms [7]. This might be due to the frequent air exchange reducing the number of sampled particles, including virus-containing particles, below the limit of virus detection [3,7]. In contrast, others detected SARS-CoV-2 in the air inside a temporary single toilet room without a ventilation system [3] and in hospital rooms with no negative pressure [10]. Even though our patients were enrolled at an early phase of confirmed COVID-19 (0-7 days), the virus load carried by patients on the study day were unknown.

Aerosol transmission and deposition are complex and affected by the room size, room air exchange frequency, the air humidity and human activity inside the room [3]. Thus, our findings are limited to institutions with similar settings. Future studies are needed to investigate the mechanisms of particle movement in air with the use of different oxygen therapy devices. Baseline particle concentrations were not measured in our study. Aerosol particles measurements were limited to two locations, future studies might consider several other positions in particular in the coronal plane close to the patients' face. It was reported that the horizontally expelled droplets including large droplets could travel a long distance [11], wearing the mask over HFNC might redirect the aerosol particle distribution to the coronal plane, where clinicians usually stand. HFNC did not generate higher aerosol particle concentrations than conventional nasal cannula and wearing a surgical/procedure mask reduced aerosol particle concentrations in the patients' vicinity and should be encouraged if it is well tolerated.

Jie Li $\oplus^{1}$, James B. Fink ${ }^{1,2}$, Ahmad A. Elshafei ${ }^{1}$, Laurel M. Stewart ${ }^{1}$, Hannah J. Barbian ${ }^{3}$, Sara H. Mirza ${ }^{1,4}$, Lena Al-Harthi ${ }^{3}$, David Vines ${ }^{1}$ and Stephan Ehrmann ${ }^{5,6}$

${ }^{1}$ Dept of Cardiopulmonary Sciences, Division of Respiratory Care, Rush University Medical Center, Chicago, IL, USA. ${ }^{2}$ Aerogen Pharma Corp, San Mateo, CA, USA. ${ }^{3}$ Dept of Microbial Pathogens and Immunity, Rush University, Chicago, IL, USA. ${ }^{4}$ Dept of Pulmonary and Critical Care, Rush University Medical Center, Chicago, IL, USA. ${ }^{5}$ CHRU Tours, Médecine Intensive Réanimation, CIC INSERM 1415, CRICS-TriggerSEP Research Network, Tours, France. ${ }^{6}$ INSERM, Centre d'étude des pathologies respiratoires, U1100, Université de Tours, Tours, France.

Correspondence: Jie Li, Dept of Cardiopulmonary Sciences, Division of Respiratory Care, Rush University Medical Center, 1620 W Harrison St, Tower LL1202, Chicago, IL 60612, USA. E-mail: Jie_Li@rush.edu

Received: 24 July 2020 | Accepted after revision: 21 Oct 2020

Author contributions: J. Li took responsibility for the integrity of the work as a whole, from inception to published article. J. Li and J.B. Fink conceived the idea. A.A. Elshafei, L.M. Stewart and J. Li implemented data collection, H.J. Barbian performed SARS-CoV-2 quantitative PCR testing, and L. Al-Harthi coordinated and directed the virus detection studies. J. Li performed data analysis and drafted the manuscript. J. Li, L. Al-Harthi, S. Ehrmann and J.B. Fink interpreted the data. J.B. Fink and S.H. Mirza supervised the process. S. Ehrmann and J.B. Fink provided critical revision on the manuscript. All authors reviewed and approved the final version.

Ethical approval: This study was approved by the institutional review board at Rush University Medical Center (approval number 20032402-IRB01).

Conflict of interest: J. Li reports receiving funding from Fisher and Paykel Healthcare Ltd and Rice Foundation, and lecture honorarium from AARC and Fisher and Paykel Healthcare Ltd. J.B. Fink is chief scientific officer for Aerogen Pharma Corp, developing drug device products for the critical care setting. A.A. Elshafei has nothing to disclose L.M. Stewart has nothing to disclose. H.J. Barbian has nothing to disclose. S.H. Mirza has nothing to disclose. L. Al-Harthi has nothing to disclose. D. Vines reports consultancy fees from Ohio Medical and grants from Teleflex Medical outside the submitted work. S. Ehrmann reports grants, personal fees and nonfinancial support from Fisher and Paykel Healthcare, and grants from Hamilton medical, during the conduct of the study; and grants, personal fees and nonfinancial support from Aerogen Ltd and La Diffusion Technique Française, outside the submitted work. 
Support statement: This study was sponsored the unrestricted grant by Fisher \& Paykel Healthcare Ltd. The company had no role in the design of the study; in the collection, analyses, or interpretation of data; in the writing of the manuscript, and in the decision to publish the results. Funding information for this article has been deposited with the Crossref Funder Registry.

\section{References}

1 Li J, Jing GQ, Scott JB. Year in review 2019: High-flow nasal cannula (HFNC) oxygen therapy for adult patients. Respir Care 2020; 65: 545-557.

2 Wang K, Zhao W, Li J, et al. The experience of high-flow nasal cannula in hospitalized patients with 2019 novel coronavirus-infected pneumonia in two hospitals of Chongqing, China. Ann Intensive Care 2020; 10: 37.

3 Dhand $\mathrm{R}, \mathrm{Li} \mathrm{J}$. Coughs and sneezes: Their role in transmission of respiratory viral infections, including SARS-CoV-2. Am J Respir Crit Care Med 2020; 202: 651-659.

4 Li J, Fink JB, Ehrmann S. High-flow nasal cannula for COVID-19 patients: low risk of bio-aerosol dispersion. Eur Respir J 2020; 55: 2000892.

5 Hui DS, Chow BK, Lo T, et al. Exhaled air dispersion during high-flow nasal cannula therapy versus CPAP via different masks. Eur Respir J 2019; 53: 1802339.

6 Leonard S, Atwood CW Jr, Walsh BK, et al. Preliminary findings on control of dispersion of aerosols and droplets during high-velocity nasal insufflation therapy using a simple surgical mask: Implications for the high-flow nasal cannula. Chest 2020; 158: 1046-1049.

7 Liu Y, Ning Z, Chen Y, et al. Aerodynamic characteristics and RNA concentration of SARS-CoV-2 aerosol in Wuhan hospitals during COVID-19 outbreak. Nature 2020; 582: 557-560.

8 Centers for Disease Control and Prevention CDC 2019-novel coronavirus (2019-nCoV) real-time RT-PCR diagnostic panel. www.fda.gov/media/134922/download

9 Gaeckle NT, Lee J, Park Y, et al. Aerosol Generation from the Respiratory Tract with Various Modes of Oxygen Delivery. Am J Respir Crit Care Med 2020; 202: 1115-1124.

10 Guo ZD, Wang ZY, Zhang SF, et al. Aerosol and surface distribution of severe acute respiratory syndrome coronavirus 2 in hospital wards, Wuhan, China, 2020. Emerg Infect Dis 2020; 26: 1583-1591.

11 Xie X, Li Y, Chwang AT, et al. How far droplets can move in indoor environments--revisiting the Wells evaporation-falling curve. Indoor Air 2007; 17: 211-225. 